\title{
FÁCIES SEDIMENTARES DA FORMAÇÃO RIO CLARO, NEOCENOZÓICO DA DEPRESSÃO PERIFÉRICA PAULISTA
}

\author{
Mário Sérgio de MELO \\ Armando Márcio COIMBRA \\ Gláucia CUCHIERATO
}

\begin{abstract}
RESUMO
Os dados das fácies sedimentares da Formação Rio Claro aqui apresentados resultam de pesquisa enfocando os depósitos neocenozóicos da porção centro-leste da Depressão Periférica Paulista, a qual objetivou a compreensão da evolução geológica da região. Os sedimentos neocenozóicos são delgados e descontínuos, sua interpretação e classificação requereram uma abordagem levando em conta, também, aspectos geomórficos (relações com níveis planálti- . cos), além dos conceitos litoestratigráficos usuais. Foram identificados cinco níveis planálticos de extensão regional, sendo que os dois mais elevados ocorrem somente nas províncias geomorfológicas do Planalto Atlântico e Cuestas Basálticas (limítrofes com a Depressão Periférica), e os três mais jovens e rebaixados ocorrem dentro dos limites da Depressão Periférica. A associação de depósitos rudáceos e couraças ferruginosas com estes níveis planálticos é sugestiva de que eles correspondam a pediplanos elaborados em fases de climas secos. A Formação Rio Claro foi reconhecida na área do platô de Rio Claro, onde é mais contínua, e na borda leste da Depressão Periférica, com ocorrências descontínuas; ocorre sobre os dois níveis planálticos principais que nivelam as colinas da região; é constituída por depósitos de sistema fluvial meandrante, formados sob clima úmido, agrupados em quatro litofácies principais: lamitos de processos gravitacionais; cascalhos e areias de canais e barras fluviais; areias finas de rompimento de diques marginais; e argilas de transbordamento em planície de inundação. Na área do platô de Rio Claro a sedimentação foi controlada pela reativação neocenozóica de falhas com movimentação vertical na estrutura de Pitanga, alto estrutural ativo durante o Mesozóico, situado a jusante do sítio deposicional. Nas ocorrências da borda leste da Depressão Periférica, a sedimentação está mais claramente associada com barramentos litológicos da drenagem (soleiras e diques de diabásio).
\end{abstract}

\section{ABSTRACT}

The Rio Claro Formation and associated deposits comprise continental Neocenozoic sediments of the Depressão Periférica (inner lowlands) of southeastern Brazil. These sediments are discontinuous and thin, and their interpretation and classification required the use of geomorphic concepts as well as the usual lithostratigraphic ones. Five planation surfaces of regional extent have been recognized; the lowest and youngest three occur within the limits of the Depressão Periférica, whereas the oldest two occur at higher levels in the neighbouring terrains. Coarse deposits and ferricretes associated with these planation surfaces suggest that they were formed during pediplanation cycles under dry climatic conditions. The Rio Claro Formation is more continuous in its type-area (near the city of Rio Claro), and is discontinuous near the eastern border of the Depressão Periférica. It lies upon the two highest planation surfaces which leveled the hills of the area, and has about the same age as these surfaces. It contains deposits of meandering fluvial system formed under humid climates, comprising four principal lithofacies: sandy and gravelly muds due to gravity processes; gravels and sands of channel lag and channel bar deposits; sands of crevasse splay deposits; and flood plain muds. In the type-area of the Rio Claro Formation accumulation was controlled by the Neogene reactivation of faults with vertical displacements in the Pitanga structural high, which were active mainly in Mesozoic times. On the eastern border of the Depressão Periférica the Neocenozoic sediments show clear association with lithological barriers (diabase sills and dykes). 


\section{INTRODUÇÃO}

O presente trabalho resulta de pesquisa realizada na porção centro-leste da Depressão Periférica Paulista, delimitada pelos paralelos $21^{\circ} 30^{\prime}$ e $23^{\circ} 00^{\prime}$ de latitude sul e meridianos $46^{\circ} 50^{\prime}$ e $48^{\circ} 00^{\prime}$ de longitude oeste (FIGURA 1), abrangendo cerca de $20.000 \mathrm{~km}^{2}$.

O objetivo da pesquisa foi o estudo da Formação Rio Claro e depósitos associados, visando contribuir para a compreensão da evolução geológica neocenozóica da região, integrando dados de geomorfogênese, paleoclimas, neotectônica e sedimentação, em parte já divulgados ou em divulgação (MELO, 1994 e 1995; CUCHIERATO \& MELO, 1995; FERNANDES \& MELO, 1996; MELO et al., 1996 e 1997).

\section{QUESTÕES SOBRE A FORMAÇÃO RIO CLARO E DEPÓSITOS ASSOCIADOS}

Algumas questões relevantes emergem da análise dos estudos precedentes referentes à Formação Rio Claro e depósitos associados.

\subsection{Natureza e idade dos depósitos}

Desde alguns dos estudos pioneiros (MORAES REGO, 1933; BJORNBERG, 1965; MEZZALIRA, 1965; BJORNBERG \& LANDIM, 1966) os depósitos atribuídos à Formação Rio Claro têm sido referidos como englobando tanto sedimentos de textura variada estratificados, fluviais, quanto coberturas arenoargilosas incoesas maciças, com outro tipo de gênese. Esta confusão de materiais com diversas origens (sedimentos, coluviões, solo) foi apontada por FULFARO \& SUGUIO (1968), que restringiram a denominação de Formação Rio Claro aos depósitos da região da cidade, de origem fluvial.

Talvez esta ambigüidade nos trabalhos que definiram a Formação Rio Claro tenha sido o fator determinante para que, em trabalhos subseqüentes de mapeamento, a unidade tenha sido estendida por vastas áreas da Depressão Periférica (ANDRADE \& SOARES, 1971; CAVALCANTE et al., 1979), englobando tanto depósitos fluviais quanto coberturas coluviais e eluviais. Por outro lado, as extensas coberturas inconsolidadas foram definidas e mapeadas, por outros autores como unidades cronológica e geneticamente correlatas à Formação Rio Claro (DAEE, 1982a e 1982b; FREITAS et al., 1979; MASSOLI, 1981; FREITAS et al., 1990, entre outros).

A gênese e idade dos depósitos fluviais da Formação Rio Claro, conforme se apresentam no platô de Rio Claro (área-tipo), naturalmente diferem da gênese e idade das extensas coberturas areno-argilosas incoesas tão comuns em vastas porções da Depressão Periférica, ocorrendo inclusive sobre os depósitos da Formação Rio Claro.

A Formação Rio Claro na sua área-tipo engloba sedimentos de textura variada de origem fluvial (FULFARO \& SUGUIO, 1968), com depósitos de fluxos de massa e lagoas restritas associados (ZAINE, 1994), situados sobre a superfície Neogênica de MARTONNE (1943). Na falta de datações absolutas, a idade da Formação Rio Claro ainda é motivo de muita controvérsia (desde recente para BJORNBERG et al., 1964b, até eocênica para FREITAS et al., 1979). A posição dos depósitos, em situação de inversão de relevo, ocupando hoje um platô elevado mais de 100 metros sobre a drenagem local, revela certa antiguidade, o que tem levado a maioria dos autores a admitir idade próxima do limite PlioPleistoceno (v.g. SOARES \& LANDIM, 1976).

As extensas coberturas incoesas arenoargilosas sem estruturas sedimentares (coluviões) são sem dúvida mais jovens que a Formação Rio Claro, a qual em vários locais apresenta-se sob estas coberturas.

\subsection{Relações da sedimentação com superfícies aplainadas}

Vários aspectos têm contribuído para que o estudo da sedimentação neocenozóica tenha buscado relações entre os depósitos e superfícies aplainadas (v.g. BJORNBERG \& LANDIM, 1966; SOARES \& LANDIM, 1976; PENTEADO, 1976; ZAINE, 1994). Entre estes aspectos, pode-se destacar:

a) evidente organização do relevo em níveis aplainados, muitas vezes sugestivos de ciclos evolutivos;

b) estreita relação, em vários casos, entre determinados sedimentos e níveis aplainados;

c) necessidade de critérios geomorfọlógicos para datação, ainda que relativa, dos sedimentos, dada a impossibilidade de datações absolutas.

O escalonamento do relevo em níveis aplainados na área estudada tem sido associado ora a oscilações paleoclimáticas, seguindo os postulados de BIGARELLA et al. (1965) e BIGARELLA \& ANDRADE (1965) (v.g. BJORNBERG \& LANDIM, 1966; PENTEADO, 1976), ora a variações nas intensidades de basculamento tectônico (SOARES \& LANDIM, 1976).

Apesar da controvérsia sobre a gênese das superfícies aplainadas, tem havido certa concordância de que as principais delas configuram um escalonamento do relevo com um significado cronológico relativo, sendo os níveis mais altos os mais antigos. Existem alguns tipos de sedimentos penecontemporâneos de alguns níveis (v.g. a Formação Rio Claro), enquanto outros, como as extensas coberturas areno-argilosas incoesas, cobrem indistintamente diversos níveis planálticos. 
2.3 Relações da sedimentação com fatores climáticos ou tectônicos

Há uma tendência, entre os adeptos da hipótese de origem climática para as superfícies aplainadas, de considerar os depósitos como correlativos da pedimentação (BJORNBERG \& LANDIM, 1966; PENTEADO, 1976). Nesta linha de hipóteses, surgem dificuldades em compatibilizar os depósitos argilosos de planície de inundação da Formação Rio Claro com o clima semi-árido admitido para a pedimentação, o que levou BJORNBERG \& LANDIM (1966) a considerar somente os sedimentos areno-argilosos maciços como correlativos das fases semi-áridas, enquanto os sedimentos argilosos de planície de inundação corresponderiam a fases mais úmidas, entre as fases de pedimentação.

PENTEADO (1976) considerou que a acumulação da Formação Rio Claro resultaria da conjugação de fatores climáticos e tectônicos.

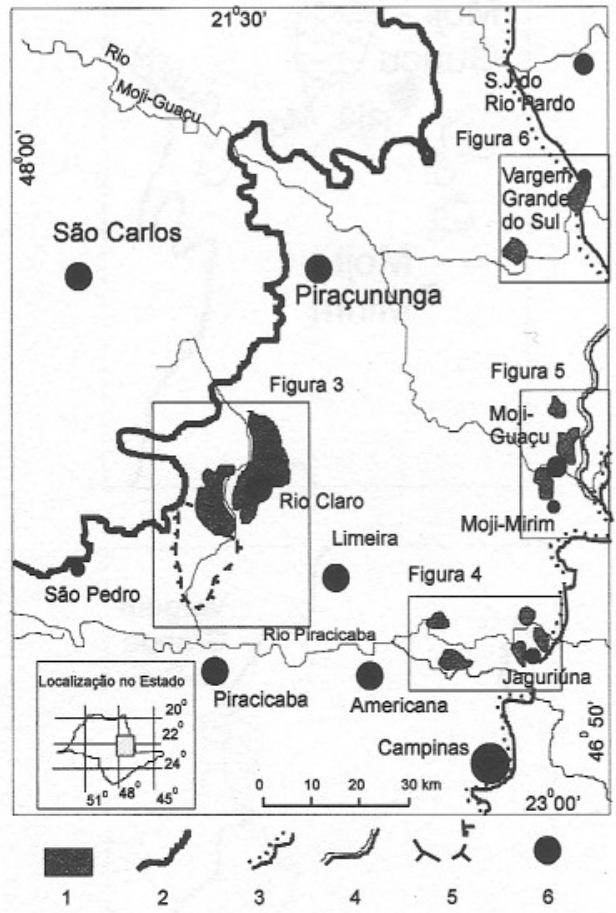

FIGURA 1 - Mapa de localização da área estudada: 1) depósitos da Formação Rio Claro; 2) limites da Depressão Periférica (conforme IPT, 1979); 3) limites da Depressão Periférica aproximadamente coincidentes com os limites das unidades da Bacia do Paraná; 4) limites das unidades da Bacia do Paraná; 5) limites aproximados da estrutura de Pitanga; 6) cidades.

Entretanto, neste caso a natureza dos depósitos (planície de inundação, de clima úmido) também não é coerente com o clima admitido para a sedimentação (semi-árido).

Vários autores admitem causas tectônicas para a sedimentação, sejam basculamentos regio- nais (SOARES \& LANDIM, 1976), seja tectônica rúptil, com formação de falhas e geração de barramentos da drenagem ou depressões (FULFARO \& SUGUIO, 1968 e 1974; PENTEADO, 1969 e 1976, FREITAS et al., 1979; ZAINE, 1994).

\section{FÁCIES SEDIMENTARES DA FORMAÇÃO RIO CLARO}

A FIGURA 2 apresenta a proposta de organização cronológica dos eventos e depósitos cenozóicos associados na área estudada.

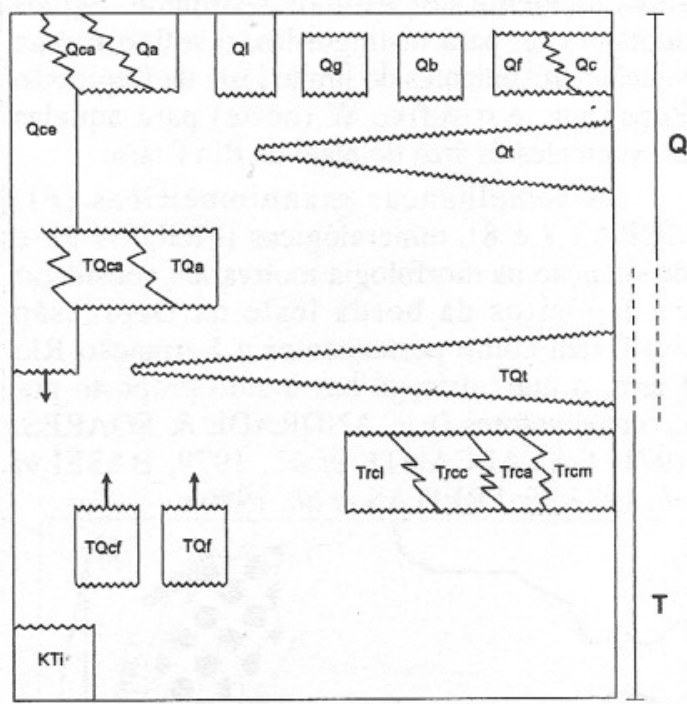

FIGURA 2 - Relações entre as unidades estratigráficas cenozóicas na porção centro-leste do Estado de São Paulo: Qa: aluviões em planícies e baixos terraços; Qca: depósitos colúvio-aluviais em baixos terraços; Q1: depósitos lacustres em depressões fechadas; Qg: depósitos lamíticos de fluxos gravitacionais; Qb: depósitos de fundo de boçorocas; Qf: depósitos rudáceos de tálus e leques aluviais junto à escarpa de cuesta; Qc: cascalhos aluviais em baixos terraços junto à escarpa de cuesta; Qt: cascalhos aluviais em terraços intermediários; Qce: depósitos colúvio-eluviais areno-argilosos em topos e rampas de colinas amplas; TQca: depósitos colúvio-aluviais em rampas e terraços elevados; TQa: depósitos aluviais em rampas e terraços elevados; TQt: cascalhos aluviais em terraços elevados; TQcf: couraças ferruginosas; TQf: depósitos rudáceos de tálus e leques aluviais separados da escarpa da cuesta; Trcl: Formação Rio Claro - lamitos de processos gravitacionais; Trcc: Formação Rio Claro - cascalhos e areias de canais e barras fluviais; Trca: Formação Rio Claro - areias finas de rompimento de diques marginais; Trcm: Formação Rio Claro - argilas de transbordamento em planície de inundação; KTi: Formação Itaqueri rudáceos, arenitos e lamitos de leques aluviais.

Esta proposta já foi em parte antecipada por MELO \& PONÇANO (1983), IPT (1992a) e MELO (1994). Baseia-se na caracterização faciológica dos sedimentos, interpretação dos processos e ambientes deposicionais, relações 
com o relevo e cronologia relativa dos eventos ligados à sua gênese.

\subsection{Distribuição dos depósitos}

Os depósitos sedimentares atribuídos à Formação Rio Claro ocorrem mais extensamente no platô de Rio Claro (FIGURA 3) e, de forma mais descontínua, nas proximidades do limite leste da Depressão Periférica, junto ao Planalto Atlântico (FIGURAS 4, 5 e 6). As amostras provenientes destas duas áreas de ocorrência (FIGURAS 7 a 9) foram tratadas separadamente nos estudos sedimentológicos adotando-se, para distingui-las, o sufixo E para aquelas provenientes do limite leste da Depressão Periférica, e o sufixo W (oeste) para aquelas provenientes da área do platô de Rio Claro.

As semelhanças granulométricas (FIGURAS 7 e 8), mineralógicas (FIGURA 9), e de situação na morfologia motivaram considerar os depósitos da borda leste da Depressão Periférica como pertencentes à Formação Rio Claro, o que, aliás, já havia sido proposto por diversos autores (v.g. ANDRADE \& SOARES, 1971; CAVALCANTE et al., 1979; BASEI et al., 1985/86; FREITAS et al., 1990).

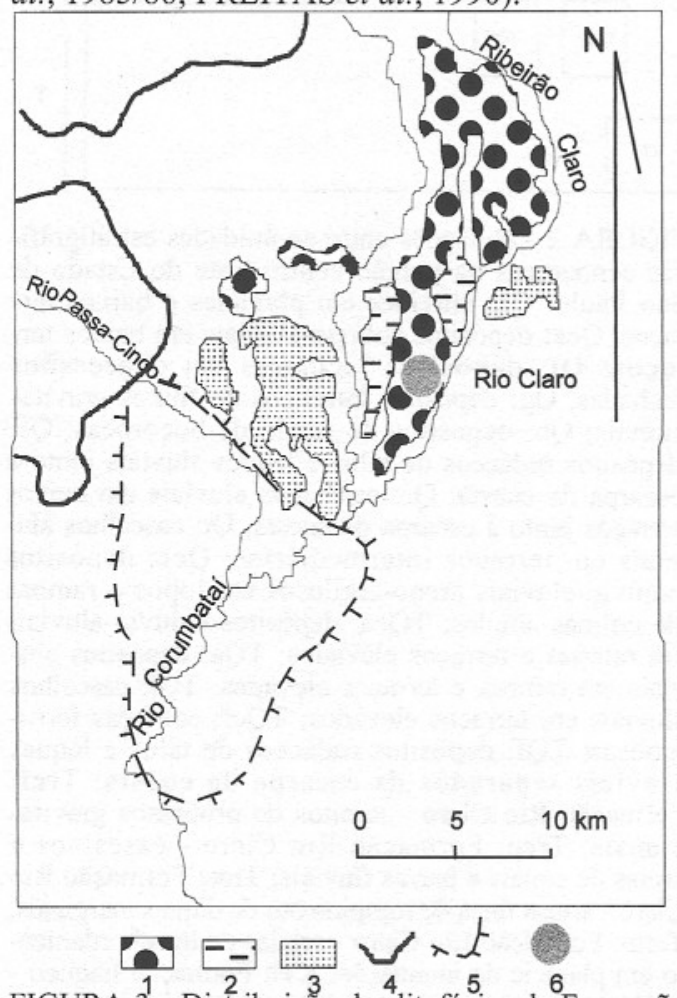

FIGURA 3 - Distribuiçẳo das litofácies da Formação Rio Claro na área do platô de Rio Claro (ver localização na FIGURA 1): 1) cascalhos e areias de canais e barras fluviais (Trcc); 2) argilas de transbordamento em planície de inundação (Trcm); 3) depósitos indiferenciados da Formação Rio Claro; 4) limites da Depressão Periférica (conforme IPT, 1979); 5) limites aproximados da estrutura de Pitanga; 6) cidades.
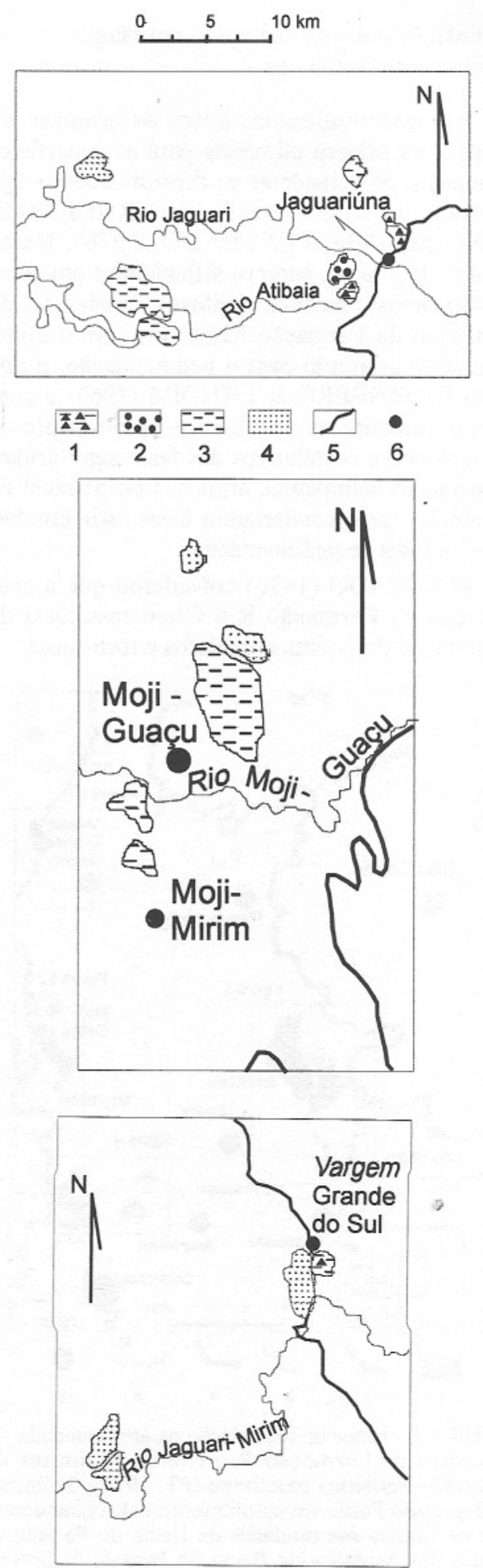

FIGURAS 4, 5, 6 - Distribuição das litofácies da Formação Rio Claro ao longo da borda leste da Bacia do Paraná (ver localização na FIGURA 1); 1) lamitos de processos gravitacionais (Trcl); 2) cascalhos e areias de canais e barras fluviais (Trcc); 3) argilas de transbordamento em planície de inundação (Trcm); 4) depósitos indiferenciados da Formação Rio Claro; 5) limites de Depressão Periférica (conforme IPT, 1979); 6) cidades. 


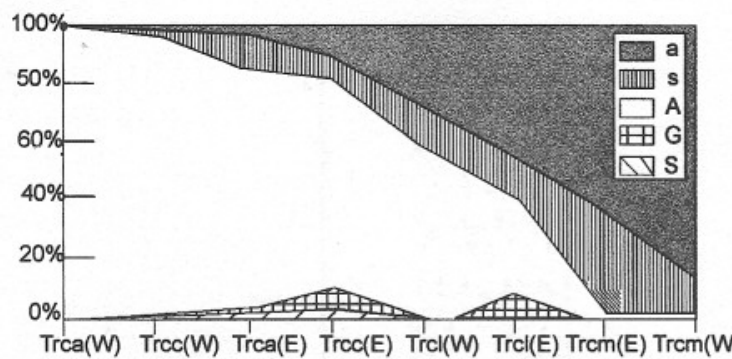

FIGURA 7 - Porcentagem média das classes texturais das litofácies da Formação Rio Claro ( $\mathrm{a}=$ argila; $\mathrm{s}=$ silte; $\mathrm{A}=$ areia; $\mathrm{G}=$ grânulos; $\mathrm{S}=$ seixos).

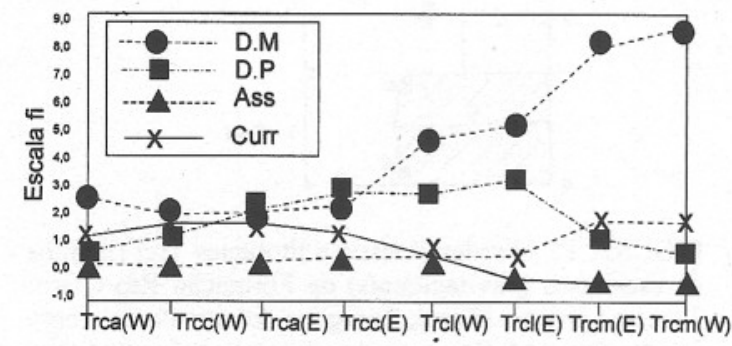

FIGURA 8 - Parâmetros estatísticos médios da fração areia das litofácies da Formação Rio Claro ( $\mathrm{DM}=$ diâmetro médio; $\mathrm{DP}=$ desvio padrão; Ass=assimetria; Cur=curtose).

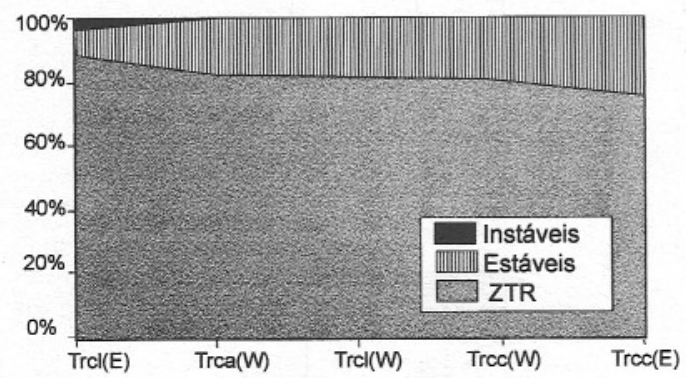

FIGURA 9 - Porcentagem média de tipos de minerais pesados transparentes das litofácies da Formação Rio Claro (ZTR=zircão+turmalina+rutilo).

\subsection{Litofácies sedimentares}

Foram reconhecidas quatro litofácies principais dentro da Formação Rio Claro.

\subsubsection{Lamitos de processos gravitacionais (Trcl)}

Esta litofácies compreende depósitos de sedimentos textural e mineralogicamente imaturos, sem estratificação ou com estratificação incipiente, contendo grande proporção de matriz fina e clastos de tamanho variado (centimétricos), dispersos na matriz (lamitos). Apresenta-se em camadas com espessura variada entre um e três metros. Ocorre sotoposta (locais RC-19 e RC-09, FIGURAS 10 e 11), intercalada e sobreposta (local BV-289, FIGURA 12) em relação aos depósitos fluviais mais típicos.

É interpretada como tendo sido formada por processos gravitacionais (corridas de lama, coluvionamento), observados sobretudo nas áreas próximas aos relevos mais acidentados do limite leste da Depressão Periférica, junto ao Planalto Atlântico.

\subsubsection{Cascalhos e areias de canais e barras fluviais (Trcc)}

Esta litofácies compreende depósitos de cascalhos, com clastos arredondados de quartzo e quartzito imbricados (FIGURA 10), intimamente associados com areias de textura variada com estratificação cruzada acanalada e tabular (FIGURAS 12 e 13). Apresenta-se em sets com espessura decimétrica e métrica.

É interpretada como depósitos de fundo de canal fluvial (cascalhos) e barras de pontal (areias) em sistema fluvial meandrante.

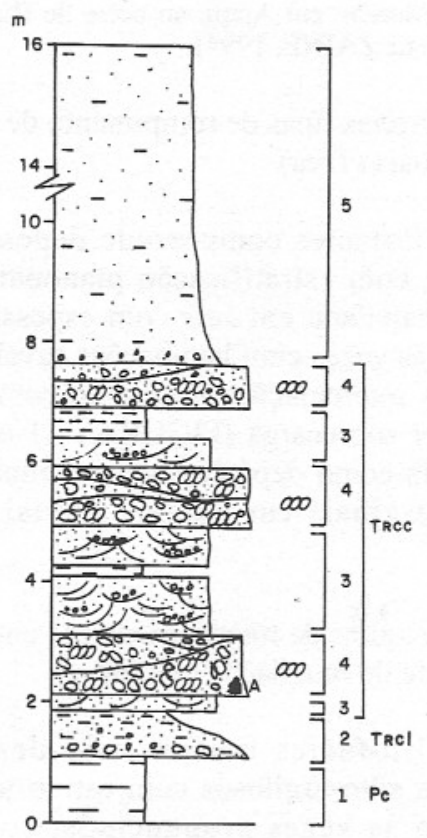

FIGURA 10 - Predominância da litofácies Trcl (lamitos de processos gravitacionais) da Formação Rio Claro: 1) argilito da Formação Corumbataí; 2) lamito; 3) cascalhos e areias (Trcc); 4) cascalhos, ocasionalmente com imbricação dos clastos (Trcc); 5) cobertura colúvio-eluvial areno-argilosa (local RC-19, Rodovia SP-191 a nordeste de Rio Claro). 


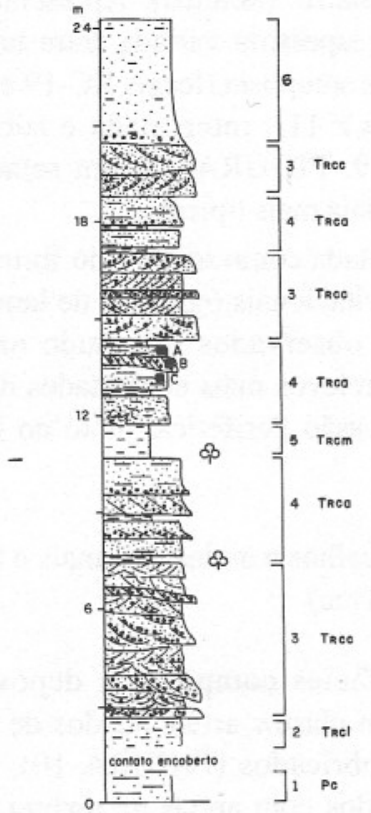

FIGURA 11 - Diversas litofácies da Formação Rio Claro associadas: 1) siltito da Formação Corumbataí; 2) lamitos (Trcl); 3) areias cascalhentas (Trcc); 4) areias finas com delgados leitos de argila com impressões de folhas e caules (Trca); 5) argilas com impressões de folhas e caules e estruturas de sobrecarga (pequenos diápiros de argila) (Trcm); 6) cobertura colúvio-eluvial areno-argilosa (local RC-09, Mineração Mandu, em Ajapi, ao norte de Rio Claro) (modificado de ZAINE, 1994).

\subsubsection{Areias finas de rompimento de diques} marginais (Trca)

Esta litofácies compreende depósitos de areia fina, com estratificação planoparalela e cruzada acanalada em sets com espessura decimétrica, às vezes com laminações cavalgantes, e delgadas intercalações de argila, com deformações por sobrecarga (FIGURAS 11 e 13). É interpretada como depósitos de rompimento de diques marginais em sistema fluvial meandrante.

\subsubsection{Argilas de transbordamento em planície de inundação (Trcm)}

Esta litofácies compreende depósitos argilosos a silto-argilosos com estratificação e laminação às vezes pronunciada, contendo impressões de folhas e caules, pistas fósseis e apresentando deformações por sobrecarga (FIGURAS 11, 12 e 13). A espessura das camadas de argilas pode variar de subdecimétrica a até uma dezena de metros. Esta litofácies é interpretada como depósitos de planície de inundação de sistema fluvial meandrante.

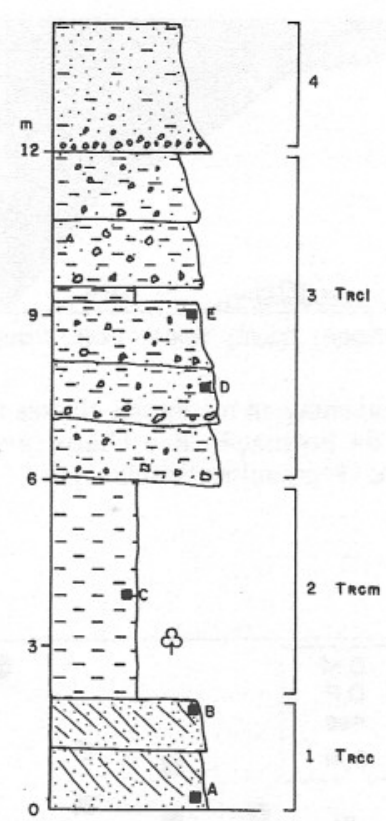

FIGURA 12 - Predominância a litofácies Trcl (lamitos de processos gravitacionais) da Formação Rio Claro: 1) areias grossas (Trcc); 2) argilas ocasionalmente com impressões de folhas e caules (Trcm); 3) lamitos com delgada intercalação de argila (Trcl); 4) cobertura colúvio-eluvial areno-argilosa (local BV-289, cava abandonada próxima a Vargem Grande do Sul).

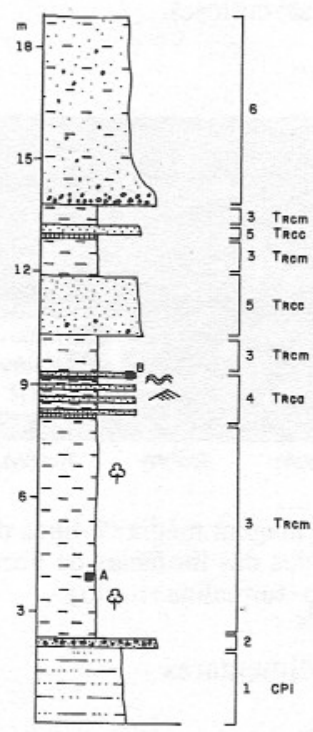

FIGURA 13 - Predominância da litofácies Trcm (argilas de transbordamento em planície de inundação) da Formação Rio Claro: 1) silte arenoso do Subgrupo Itararé; 2) conglomerado basal com matriz arenosa; 3) argila laminada com impressões de folhas e caules (Trcm); 4) intercalações de argilas e areias com marcas onduladas, laminações cavalgantes e crostas limoníticas (Trca); 5) areias sem estratificação visível (Trcc); 6) cobertura colúvio-eluvial arenoargilosa (local CA-373, rodovia Paulínia-Cosmópolis, na margem direita do rio Atibaia). 


\subsubsection{Ocorrência das litofácies}

Além destas quatro litofácies principais, a Formação Rio Claro apresenta também delgado horizonte de conglomerado basal (FIGURA 13), cuja constituição reflete a contribuição das rochas sedimentares do substrato.

Os mapas das FIGURAS 3 a 6 mostram as áreas de predominância das diferentes litofácies, quando a distinção é possível. Não são mapeadas áreas de predominância da litofácies Trca, pois ela ocorre sempre subordinada em relação às demais.

Quando não foi possível definir a litofácies predominante, seja pela escassez de afloramentos, seja pela presença de várias litofácies associadas, utilizou-se no mapa a simbologia Trci (depósitos indiferenciados da Formação Rio Claro).

\subsection{Fósseis}

Os primeiros relatos de fósseis em sedimentos posteriormente atribuídos à Formação Rio Claro são de MEZZALIRA (1961/62), que referiu-se a prováveis restos de monocotiledôneas. No mesmo trabalho referiu-se a folhas atribuídas às ordens Myrtales, Ranales, Ebenales e Rutales no jazigo de Vargem Grande do Sul, aqui atribuído à Formação Rio Claro.

Seguiram-se os relatos de BJORNBERG et al. (1964b), que identificaram nos "sedimentos modernos" do platô de Rio Claro as famílias Nympheaceae, Potamogetonaceae ou Alismataceae (Helobiae), semelhantes a formas aquáticas viventes.

DUARTE \& REZENDE-MARTINS (1983 e 1985) estudaram diversas impressões de folhas provenientes do jazigo de Vargem Grande do Sul, e identificaram vários gêneros, interpretados como indicativos de uma cobertura vegetal semelhante ao cerradão, com árvores de menor porte e com umidade menor que a mata pluvial tropical.

MARTINS-NETO (1989) descreveu asa de inseto do jazigo de Vargem Grande do Sul, atribuindo-a a um homóptero cercopídeo, com características não verificáveis em cercopídeos recentes, o que o levou a sugerir idade miocênica ou pliocênica para a forma encontrada.

ZAINE (1994) descreveu, na área do platô de Rio Claro, restos vegetais indeterminados, restos semelhantes aos descritos por BJORNBERG et al. (1964b), e ainda oogônios de carófitas e impressões atribuídas a angiosperma e pteridófita.

Durante os levantamentos de campo ora realizados foram observadas impressões de folhas e caules em diversos afloramentos (FIGURAS 11, 12 e 13). Todas as formas presentes nas amostras coletadas (examinadas pelo Paleontólogo Fernando Cilento Fittipaldi, do IG-SMA-SP) mostram provável relação taxonômica com formas atuais. A maioria das formas é atribuída às Magnoliopsida, aparecendo também prováveis fragmentos de Liliopsida sugerindo, com dúvidas, a família Typhaceae. Destaca-se uma folha atribuída ao gênero Maytenus, já descrita anteriormente no jazigo de Vargem Grande do Sul por DUARTE \& REZENDE-MARTINS (1983). Este gênero ocorre ainda hoje em todo o Brasil, predominando nas zonas tropical e subtropical.

No local CA-373 (FIGURA 13) foi encontrada, também, uma pista fóssil atribuída a um provável crustáceo anostráceo de água doce, o que seria um registro inédito no Terciário brasileiro (FERNANDES \& MELO, 1996).

Delgados leitos centimétricos escuros, portadores de matéria orgânica decomposta, incluídos na litofácies Trcm do local RC-09 (FIGURA 11), foram analisados quanto ao seu conteúdo palinológico, pelo Geólogo Mitsuru Arai (PETROBRÁS-CENPES). Infelizmente mostraram-se estéreis, apesar da presença de alguns restos orgânicos que poderiam ser palinomorfos severamente oxidados.

De modo geral, o conteúdo paleontológico dos depósitos atribuídos à Formação Rio Claro, apesar de não escasso, ainda não permitiu avançar muito com relação a interpretações cronológicas e paleoambientais, o que poderia ser realizado com estudos específicos.

\subsection{Ambientes deposicionais e paleoclima}

As litofácies reconhecidas na Formação Rio Claro indicam sedimentação em ambiente fluvial meandrante, para o qual se admite baixos gradientes e clima úmido (v.g. COLLINSON, 1986).

Os fósseis vegetais encontrados têm sido interpretados como indicadores de situações variando de áreas alagadas (BJORNBERG et al. 1964b) a cerradão com umidade menor que a mata pluvial tropical (DUARTE \& REZENDEMARTINS, 1985). 
A quase ausência de minerais pesados instáveis e os valores de ZTR relativamente altos mesmo para os depósitos da borda leste da Depressão Periférica (FIGURA 9) são sugestivos de condições de intemperismo químico pronunciado, sob clima quente e úmido. A abundância de caulinitas detríticas e a inexistência de argilas esmectíticas nos sedimentos da Formação Rio Claro (MELO et al., 1997), apesar de fontes portadoras destas argilas (unidades Itararé-Aquidauana e Formação Corumbataí) são outras evidências das condições de pronunciado intemperismo químico.

\subsection{Paleocorrentes}

Foram medidas estratificações cruzadas e clastos imbricados da litofácies Trcc (TABELA 1). As estratificações cruzadas comumente são acanaladas, mas partiu-se do princípio que um número suficiente de medidas tenderia a dar como azimute médio um valor próximo da paleocorrente, apesar de grande dispersão dos dados. Isto pode explicar em parte os altos valores de desvio padrão na TABELA 1.

Os resultados obtidos (FIGURA 14), embora em pequeno número, mostram paleocorrente com o sentido geral do rio Corumbataí atual.

TABELA 1 - Azimute da paleocorrente de sedimentos da Formação Rio Claro (VM=azimute do vetor médio; $\mathrm{S}=$ desvio padrão angular; $\mathrm{RC}=$ razão de consistência em porcentagem; os valores de VM e $\mathrm{S}$ correspondem a azimutes em graus, calculados de acordo com POTTER \& PETTIJOHN, 1977 e MATOS, 1995) (FIGURA 14).

\begin{tabular}{|c|c|c|c|c|c|c|}
\hline local & $\begin{array}{c}\text { unidade } \\
\text { litoestratigráfica }\end{array}$ & dado & $\begin{array}{c}\text { número de } \\
\text { dados }\end{array}$ & VM & $\mathrm{S}$ & $\mathrm{RC}$ \\
\hline RC-08 & Trc & $\begin{array}{c}\text { estratificação } \\
\text { cruzada }\end{array}$ & 45 & 138 & 62 & 41 \\
\hline RC-09 & Trc & $\begin{array}{c}\text { estratificação } \\
\text { cruzada }\end{array}$ & 38 & 163 & 63 & 39 \\
\hline RC-15 & Trc & $\begin{array}{c}\text { estratificação } \\
\text { cruzada }\end{array}$ & 13 & 289 & 56 & 53 \\
\hline RC-19 & Trc & $\begin{array}{c}\text { clastos } \\
\text { imbricados }\end{array}$ & 12 & 176 & 32 & 84 \\
\hline
\end{tabular}

\section{RELAÇÕES ESTRATIGRÁFICAS}

$\mathrm{Na}$ área do platô de Rio Claro, a Formação Rio Claro aparece sempre sobreposta à Formação Corumbataí, do Permiano Superior (FIGURAS 10 e 11). Na borda leste da Depressão Periférica aparece sobreposta ao Subgrupo Itararé e Formação Aquidauana e, em Vargem Grande do Sul e Jaguariúna, aparece diretamente sobre o embasamento pré-cambriano.

A Formação Rio Claro é recoberta por depósitos colúvio-eluviais areno-argilosos (FIGURAS 10,11, 12 e 13) e por depósitos lamíticos de fluxos gravitacionais, tendo sido estas as únicas relações de contato observadas nos trabalhos de campo.

\section{ASSOCIAÇÕES COM OS NIVEIS PLANÁLTICOS}

Foram mapeados cinco níveis planálticos de extensão regional, designados A, I, B, Bd e R (do mais elevado para o mais rebaixado) (CUCHIERATO \& MELO, 1995; MELO, 1995), correspondentes a níveis identificados em regiões vizinhas, e em parte já referenciados na área de estudo por autores precedentes (MARTONNE, 1943; ALMEIDA, 1964; AB'SÁBER, 1972; PENTEADO, 1969 e 1976; IPT, 1992a e 1992b).

Os níveis $\mathrm{B}, \mathrm{Bd}$ e $\mathrm{R}$ ocorrem dentro dos limites da Depressão Periférica. Os dois mais antigos e elevados (B e Bd) são os mais extensos, e nivelam o relevo colinoso da região, sendo considerados sincrônicos. São englobados na superfície Neogênica. O mais jovem (R), embutido abaixo dos anteriores, aparece somente junto ao vale dos rios Tietê e Piracicaba.

Tanto na área do platô de Rio Claro quanto na borda leste da Depressão Periférica, a Formação Rio Claro ocorre sobre o nível planáltico $\mathrm{Bd}$. A única exceção é a ocorrência de Vargem Grande do Sul, que se situa sobre o nível planáltico $\mathrm{B}$, elevado em relação ao $\mathrm{Bd}$.

Admitindo-se que a ocorrência de Vargem Grande do Sul realmente corresponda à Formação Rio Claro, ela vem reforçar a constatação de que a Depressão Periférica é nivelada por mais de uma superfície de mesma idade (ALMEIDA, 1964; AB'SÁBER, 1969b; MODENESI, 1974; PENTEADO, 1976), correspondentes à superfície Neogênica de MARTONNE (1943). 


\section{IDADE}

A idade da Formação Rio Claro tem sido muito discutida. Com base nos fósseis vegetais nela reconhecidos, BJORNBERG et al. (1964a e 1964b) admitiram idade recente, enquanto BJORNBERG \& LANDIM (1966) atribuíramlhe idade neocenozóica, da mesma forma que FULFARO \& SUGUIO (1968).

AB'SÁBER (1969a) considerou-a pleistocênica inferior, com base no fato de $o$ assoalho da bacia de acumulação configurar uma ampla superfície alveolar rasa, ligeiramente embutida abaixo da superfície Neogênica.

FULFARO \& SUGUIO (1974) atribuíramlhe idade miocênica, com base na hipotética correlação com eventos tectônicos e sedimentação continentais.

SOARES \& LANDIM (1976) consideraram-na como posicionada na "superfície dos médios interflúvios" ou "superfície do médio Tietê" de ALMEIDA (1964), cuja elaboração teria ocorrido no limite Plioceno-Pleistoceno, idade inferida com base em estimativa de taxa de rebaixamento erosivo.

PENTEADO (1976) considerou pliocênica a fase de pediplanação que elaborou o primitivo assoalho da bacia de Rio Claro, e pleistocênica inferior a acumulação de sedimentos em alvéolos escalonados pela reativação de falhas.

CAVALCANTE et al. (1979) consideraram-na quaternária, com base nas interpretações de BJORNBERG \& LANDIM (1966).

DUARTE \& REZENDE-MARTINS (1985) propuseram idade holocênica para os depósitos de Vargem Grande do Sul, com base na grande porcentagem, entre os vegetais fósseis presentes, de famílias atualmente em plena evolução.

MARTINS-NETO (1989) sugeriu idade a partir do Mioceno, não ultrapassando o Plioceno, para o inseto homóptero cercopídeo encontrado em Vargem Grande do Sul, baseando-se em diferenças anatômicas em relação aos cercopídeos recentes.

ZAINE (1994) admitiu que a idade da Formação Rio Claro na área-tipo seria mais antiga do que o geralmente aceito, devendo remontar, pelo menos, ao Mioceno. Baseou tal conclusão na constatação de que os depósitos estão truncados por estruturas atribuídas à fase de tectônica distensiva supostamente ocorrida no Mesozóico/Paleógeno, o que é um argumento muito questionável porque, por outro lado, admitiu que a deposição da Formação Rio Claro marcaria o fecho deposicional do ciclo que elaborou a superfície Neogênica de MARTONNE (1943).
Os elementos disponíveis até o momento dão conta de que a idade da Formação Rio Claro ainda deve ser considerada indefinida, apesar de alguns argumentos paleontológicos e geomorfológicos apontarem para uma idade neogênica (Mioceno-Plioceno). Neste sentido, é significativa a estreita correlação da Formação Rio Claro com os níveis planálticos $\mathrm{Bd}$ e $\mathrm{B}$ (principalmente o primeiro), que nivelam as colinas da Depressão Periférica, sendo englobados na superfície Neogênica. Apesar de esta superfície também não apresentar nenhuma datação absoluta, parece aceitável que corresponda à primeira fase glacial global, ocorrida no Plioceno Superior (2,4-2,3 Ma), MÖRNER, 1991, quando se iniciou a alternância de fases glacias e interglaciais características do Quaternário, em conseqüência de padrões de circulação oceânica e atmosférica induzidos por reorganizações tectônicas globais (MÖRNER, 1993).

\section{CORRELAÇÕES}

Possíveis unidades cronocorrelatas da Formação Rio Claro no Estado de São Paulo são a Formação Pariqüera-Açu do rio Ribeira do Iguape (MELO, 1990) e a Formação Pindamonhangaba da Bacia de Taubaté (RICCOMINI, 1989), esta última considerada, também, neogênica (MANCINI \& RICCOMINI, 1994). A situação geomorfológica destas três unidades (associação com níveis planálticos equivalentes de idade neogênica), a presença de fatores paleoclimáticos e paleoambientais comuns apontam para possivel sincronismo deposicional, embora as condições tectônicas admitidas apresentem certas diferenças: calmaria tectônica entre dois eventos transcorrentes para a Formação Pindamonhangaba, esforços distensivos E-W para a Formação Pariquera-Açu, reativação de falhas com movimentação vertical para a Formação Rio Claro.

\section{FATORES ASSOCIADOS À GÊNESE DOS SEDIMENTOS}

A observância da FIGURA 14 mostra:

a) nítida relação dos sedimentos da Formação Rio Claro na sua área-tipo com o nível planáltico $\mathrm{Bd}$;

b) paleocorrentes dos depósitos da Formação Rio Claro indicando paleodrenagem com sentido geral de NNE para SSW, similar à drenagem atual;

c) localização dos sedimentos a montante da estrutura de Pitanga; 
d) localização dos sedimentos a montante de barramentos litológicos representados por soleiras de diabásio, sendo as principais aquelas situadas junto às confluências dos rios Corumbataí/Claro e Passa-Cinco/Cabeça;

e) existência de áreas soerguidas do nível planáltico $\mathrm{Bd}$ (normalmente nivelado em torno de 600 metros) na margem esquerda do rio Corumbataí (até $678 \mathrm{~m}$ ) e margem direita do rio Passa-Cinco (até $670 \mathrm{~m}$ );

f) localização dos sedimentos em bloco rebaixado a montante de prováveis falhas com movimentação vertical reativadas no Neocenozóico, situadas aproximadamente ao longo do vale dos rios Corumbataí (direção NESW) e Passa/Cinco (direção NW-SE).

Estas observações indicam que o fator determinante da acumulação de sedimentos neocenozóicos na área da cidade de Rio Claro foi a atividade de falhas com movimentação vertical na área da estrutura de Pitanga.

As principais destas falhas são aquelas dos rios Passa/Cinco (direção NW-SE) e Corumbataí (direção NE-SW). A falha do rio Passa/Cinco já foi mapeada e referida há muito tempo (v.g. ANDRADE \& SOARES, 1971; BRANDT NETO et al., 1981), pois é uma estrutura que trunca nitidamente as unidades paleozóicas da Bacia do Paraná e encaixa diques de diabásio, constituindo o limite norte da estrutura de Pitanga. Trata-se, portanto, de uma estrutura com atividade marcante no Mesozóico. Sua reativação neocenozóica é indicada principalmente pela acumulação dos depósitos da Formação Rio Claro e o soerguimento do nível planáltico $\mathrm{Bd}$. Tal soerguimento, estimado com base nas cotas de topo atuais do nível $\mathrm{Bd}$, parece ter sido da ordem de grandeza da espessura admitida para a Formação Rio Claro $(20$ a 40m, segundo COTTAS, 1983; ZAINE, 1994).

A falha do rio Corumbataí situa-se na porção central da estrutura de Pitanga, e não deve ter tido movimentação significativa durante a fase principal de atividade na estrutura, no Mesozóico. A falha parece ter sido importante sobretudo durante a reativação neocenozóica na área. Da mesma forma que para a falha do rio Passa/Cinco, sua atividade neocenozóica é indicada principalmente pela acumulação dos depósitos da Formação Rio Claro e soerguimento do nível planáltico $\mathrm{Bd}$, estimandose igualmente desnivelamentos da ordem de grandeza da espessura admitida para a Formação Rio Claro (20 a 40 m).
A par da atividade de falhas com movimentação vertical, barramentos litológicos, representados por soleiras de diabásio, também influenciaram a acumulação dos depósitos da Formação Rio Claro.

A estreita associação dos sedimentos neocenozóicos na área da cidade de Rio Claro com o nível planáltico $\mathrm{Bd}$ indica que este nível encontrava-se preservado, ainda não entalhado, durante a sedimentação. Isto sugere que a reativação neocenozóica das falhas da área da estrutura de Pitanga tenha ocorrido logo após o afeiçoamento do nível planáltico Bd.

Os depósitos atribuídos à Formação Rio Claro situados nas proximidades da borda leste da Depressão Periférica (Vargem Grande do Sul, rio Jaguari-Mirim, Moji-Guaçu, MojiMirim, Jaguariúna, Cosmópolis, Paulínia) apresentam algumas diferenças em relação àqueles situados na área da cidade de Rio Claro:

a) situam-se principalmente sobre o nível planáltico $\mathrm{Bd}$, mas também sobre o nível planáltico B (relativamente mais elevado), em Vargem Grande do Sul;

b) situam-se sempre a montante de barramentos litológicos, representados por soleiras e diques de diabásio, muito comuns neste setor da Depressão Periférica Paulista; tais barramentos condicionam ainda hoje alargamentos dos vales e sedimentação fluvial a montante, o que é observado nos rios Jaguari-Mirim, Moji-Guaçu, Jaguari e Atibaia;

c) não se observam evidências nem estruturais nem morfológicas de reativações tectônicas neocenozóicas que pudessem ter condicionado a sedimentação.

Estas observações sugerem que o fator determinante da acumulação de sedimentos da Formação Rio Claro na borda leste da Depressão Periférica tenha sido a presença dos barramentos litológicos. Entretanto, não se pode descartar a hipótese de que discretas reativações tectônicas neocenozóicas tẹnham se associado aos barramentos litológicos no condicionamento da sedimentação, embora não tenham sido encontradas evidências destas reativações.

Assim, dois são os fatores principais associados à gênese dos sedimentos atribuídos à Formação Rio Claro, com importância relativa distinta, conforme a área considerada:

a) na área da cidade de Rio Claro, o principal fator foi a movimentação de falhas com deslocamento vertical na área da estrutura de Pitanga, que determinou o barramento estrutural da drenagem e formação de um bloco rebaixado, onde se acumularam os sedimentos; tais falhas 
em parte correspondem à reativação neocenozóica de estruturas mais antigas, mesozóicas (como é o caso da falha NW-SE do rio Passa/Cinco), e em parte tiveram sua atividade principal no Neocenozóico (como é o caso da falha NE-SW do rio Corumbataí); barramentos litológicos representados por soleiras de diabásio atuaram como fator adicional para a sedimentação; b) para os depósitos das proximidades da borda leste da Depressão Periférica, o fator determinante da sedimentação parece ter sido a presença de barramentos litológicos representados por soleiras e diques de diabásio, não se encontrando ali evidências de reativações tectônicas neocenozóicas.

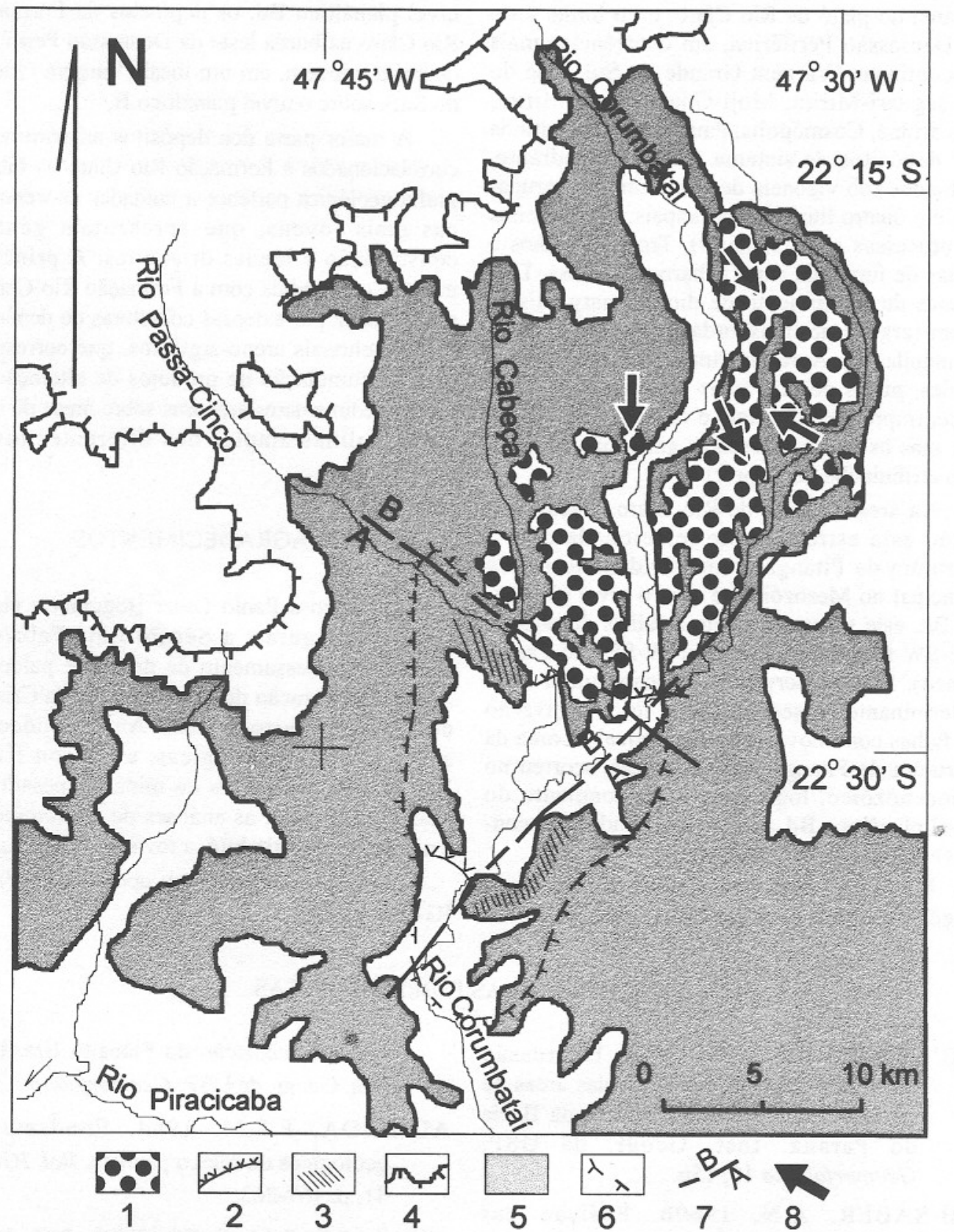

FIGURA 14 - Relações dos depósitos da Formação Rio Claro na sua área-tipo com as estruturas e feições geomorfológicas mais importantes: 1) sedimentos da Formação Rio Claro; 2) soleiras de diabásio; 3) áreas soerguidas do nível planáltico Bd; 4) escarpas de cuesta; 5) nível planáltico Bd; 6) limites aproximados da estrutura de Pitanga; 7) falhas com movimentação vertical reativadas no Neocenozóico; 8) azimute da paleocorrente de depósitos da Formação Rio Claro. 


\section{CONCLUSÕES}

Os estudos realizados na porção centro-leste da Depressão Periférica Paulista enfocaram a Formação Rio Claro e depósitos associados (caracterização, distinção, gênese, associação com o relevo), visando contribuir para a compreensão da evolução geológica neocenozóica na área.

A Formação Rio Claro $(\mathrm{Trc})$ é reconhecida na área do platô de Rio Claro, e no limite leste da Depressão Periférica, em ocorrências mais descontínuas (Vargem Grande do Sul, vale do rio Jaguari-Mirim, Moji-Guaçu, Moji-Mirim, Jaguariúna, Cosmópolis, Paulínia). É constituída por depósitos de sistema fluvial meandrante, formados sob vigência de clima úmido, agrupados em quatro litofácies principais: Trcl (lamitos de processos gravitacionais), Trcc (cascalhos e areias de fundo de canal e barras fluviais), Trca (areias de rompimento de diques marginais) e Trcm (argilas de transbordamento, em planície de inundação). Apresenta impressões de folhas e caules, pistas de prováveis crustáceos de água doce, impressão de inseto e oogônios de carófitas, mas os fósseis presentes ainda não permitiram atribuir-lhe idade precisa.

$\mathrm{Na}$ área do platô de Rio Claro, a sedimentação está estreitamente relacionada com a estrutura de Pitanga (com atividade tectônica principal no Mesozóico) e com o nível planáltico Bd, este soerguido junto a falhas de direção NE-SW (rio Corumbataí) e NW-SE (rio PassaCinco). Estas observações indicam que o fator determinante da sedimentação foi a reativação de falhas com movimentação vertical na área da estrutura de Pitanga. Tal reativação ocorreu no Neocenozóico, logo após o afeiçoamento do nível planáltico $\mathrm{Bd}$, quando este ainda se encontrava muito pouco entalhado.

Não foram observadas evidências de reativações tectônicas associadas aos depósitos atribuídos à Formação Rio Claro situados na borda leste da Depressão Periférica, embora não se possa excluir a hipótese de que tais reativações tenham ocorrido, ainda que muito atenuadas. Ali, a sedimentação está mais claramente associada à existência de barramentos litológicos (soleiras e diques de diabásio), que controlam ainda hoje alargamentos dos vales e sedimentação fluvial a montante. Além de associar-se ao nível planáltico $\mathrm{Bd}$, os depósitos da Formação Rio Claro na borda leste da Depressão Periférica ocorrem também, em um local (Vargem Grande do Sul), sobre o nível planáltico $\mathrm{B}$.

A maior parte dos depósitos anteriormente correlacionados à Formação Rio Claro na bibliografia geológica pertence a unidades neocenozóicas mais jovens, que apresentam gênese, constituição e idades diferentes. A principal unidade confundida com a Formação Rio Claro é representada por extensas coberturas de depósitos colúvio-eluviais areno-argilosos, que correspondem à acumulação de produtos de alteração de rochas sedimentares arenosas sobre áreas de relevo de colinas amplas nos diferentes níveis planálticos.

\section{AGRADECIMENTOS}

Agradeço a Paulo Cesar Boggiani a elaboração das figuras; a Sérgio Luís Fabris de Matos, o processamento de dados de paleocorrentes e preparação dos mapas; a Maria Cristina de Moraes e Jairo de Sant'Anna Taddeo, as análises sedimentológicas; a Wilson Hideo Yamamoto, as análises de minerais pesados; a Max Brandt Neto, as análises de argilominerais e a Thomas R. Fairchild, a revisão do abstract.

Trabalho realizado com apoio da FAPESP, IG-USP e IPT.

\section{REFERÊNCIAS BIBLIOGRÁFICAS}

AB'SÁBER, A.N. 1969a. A Depressão Periférica Paulista: um setor das áreas de circundesnudação pós-cretácica da Bacia do Paraná. Inst. Geogr. da USP, Geomorfologia 15, 15p.

AB'SÁBER, A.N. 1969b. Posição das superfícies aplainadas no Planalto Brasileiro. Campinas: Notícia Geomorfológica, v.5, n.9/10, p. 52-54.

AB'SÁBER, A.N. 1972. Participação das depressões periféricas aplainadas na compartimentação do Planalto Brasileiro. Inst. Geogr. da USP, Geomorfologia 26.

ALMEIDA, F.F.M. 1964. Fundamentos geológicos do relevo paulista. Bol. IGG, n. 41 , p. $167-263$.

ANDRADE, S.M. \& SOARES, P.C. 1971. Geologia de semi-detalhe do centroleste de São Paulo. Ponta Grossa: PETROBRÁS/DESUL, Relatório DESUL, n. $407,46 \mathrm{p}$. 
BASEI, M.A.S., CAMPOS NETO, M.C., BERGMANN, M. \& FIGUEIREDO, M.C.H. 1985/86. Geologia da folha de Amparo 1:50.000. São Paulo: SICCTPRÓ-MINÉRIO/IG-USP, 3 v.

BIGARELLA, J.J. \& ANDRADE, G.O. 1965. Contribution to the study of the Brazilian Quaternary. In: WRIGHT, JR., H.E., FREY, D.G. (Ed.), International studies on the Quaternary. New York: Geol. Soc. Am., p. 443-451. (GSA Special Paper, 84)

BIGARELLA, J.J., MOUSINHO, M.R. \& SILVA, J.X. 1965. Pediplanos, pedimentos e seus depósitos correlativos no Brasil. Curitiba: Bol. Par. Geogr., n. 16/17, p. 117-151.

BJORNBERG, A.J.S. 1965. Sedimentos póscretácicos do leste do Estado de São Paulo. São Carlos, 132p. (Tese LivreDocência, Escola de Engenharia de São Carlos-USP)

BJORNBERG, A.J.S. \& LANDIM, P.M.B. 1966. Contribuição ao estudo da Formação Rio Claro (Neocenozóico). São Paulo: Bol. Soc. Bras. Geol., v. 15, n. 4, p. 43-68.

BJORNBERG, A.J.S., MACIEL, A.C. \& GANDOLFI, N. 1964a. Nota sobre os depósitos modernos na região de Rio Claro-São Paulo: Pub. Esc. Eng. São Carlos, n. 106, p. 21-36. (Geologia n. 11)

BJORNBERG, A.J.S., LANDIM, P.M.B. \& MEIRELLES FILHO, G.M. $1964 b$. Restos de plantas modernas em níveis elevados na região de Rio Claro (SP): Pub. Esc. Eng. São Carlos, n. 106, p. 3757. (Geologia n. 11)

BRANDT NETO, M., COIMBRA, A.M., BARELLI, N. \& SPILLER, L.R. 1981. Sedimentos da Serra de Itaqueri. In: MESA REDONDA A FORMAÇÃO BAURU NO ESTADO DE SÃO PAULO E REGIÕES ADJACENTES, 1986, São Paulo. Pub. Espec. São Paulo: SBG/SP, n. 7, p. 63-80.

CAVALCANTE, J.C., CUNHA, H.C. da S., CHIEREGATI, L.A., KAEFER, L.Q., ROCHA, J.M. da, DAITX, E.C., COUTINHO, M.G. da N., YAMAMOTO, K., DRUMOND, J.B.V., ROSA, D.B. \& RAMALHO, R. 1979. Projeto Sapucaí. Estados de São Paulo, Minas Gerais e Rio de Janeiro: relatório final de geologia.
Brasília: DNPM/CPRM, Superintendência Regional de São Paulo, 299p. il. (DNPM, Série Geologia, 5. Secção Geologia Básica, 2)

COLLINSON, J.D. 1986. Alluvial sediments. In: READING, H.G. (Ed.). Sedimentary environments and facies, London: Blackwell, p. 20-62.

COTTAS, L.R. 1983. Estudos geológicosgeotécnicos aplicados ao planejamento urbano de Rio Claro-SP. Tese de doutorado apresentada ao Instituto de Geociências da USP.

CUCHIERATO, G. \& MELO, M.S. 1995. Níveis planálticos na porção centro-leste do Estado de São Paulo. In: SIMPÓSIO DE GEOLOGIA DO SUDESTE, 10., 1995, São Paulo. Boletim de Resumos. SBG/SP, p.94.

DAEE-DEPARTAMENTO DE ÁGUAS E ENERGIA ELÉTRICA. 1982a. Mapa geológico do Estado de São Paulo, folha Campinas escala 1:250.000. São Paulo: Convênio DAEE/UNESP, Instituto de Geociências e Ciências Exatas/Rio Claro.

DAEE-DEPARTAMENTO DE ÁGUAS E ENERGIA ELÉTRICA. 1982b. Mapa geológico do Estado de São Paulo, folha Ribeirão Preto escala 1:250.000. São Paulo: Convênio DAEE/UNESP, Instituto de Geociências e Ciências Exatas/Rio Claro.

DUARTE, L. \& REZENDE-MARTINS, A.F.P. 1983. Contribuição ao conhecimento da flora cenozóica do Brasil: jazigo Vargem Grande do Sul, SP. Série Taubaté I. An. Acad. bras. Ci., v. 55, n. 1, p. 109-121.

DUARTE, L. \& REZENDE-MARTINS, A.F.P. 1985. Contribuição ao conhecimento da flora cenozóica do Brasil: jazigo Vargem Grande do Sul, SP. Série Taubaté II. In: DNPM Coletânea de Trabalhos Paleontológicos. Brasília: MME, DNPM, p.565-571. (Série Geologia n. 27)

FERNANDES, A.C.S. \& MELO, M.S. 1996. Ocorrência de pistas de artrópodes na Formação Rio Claro, Neocenozóico do Estado de São Paulo. An. Acad. bras. Ci., v. 68, n.2, p. 277 .

FREITAS, R.O., MEZZALIRA, S., ODA, G.H., VIEIRA, P.C., TORRES, C.C., HACHIRO, J., TOMINAGA, L.K., 
DEHIRA, L.K., MASSOLI, M., AZEVEDO, A.A.B. \& PRESSINOTTI, M.M.N. 1979. Projeto levantamento geológico de formações superficiais. In: SIMPÓSIO REGIONAL DE GEOLOGIA, 2., 1979. Rio Claro. Atas. Rio Claro: SBG, v. 2, p. $263 / 277$.

FREITAS, R.O., VIEIRA, P.C. \& MEZZALIRA, S. 1990. A Formação Piraçununga na região de Vargem Grande do Sul, SP. Aplicação da técnica de perfis sedimentares. Rev. $I G$, v.11, n. 2, p.35-48.

FULFARO, V.J. \& SUGUIO, K. 1968. A Formação Rio Claro, Neocenozóico, e seu ambiente de deposição. IGG, Rev. do Inst. Geogr. Geol., São Paulo: v. 20, n. único, p. $45-60$.

FULFARO, V.J. \& SUGUIO, K. 1974. O Cenozóico paulista: gênese e idade. In: CONGRESSO BRASILEIRO DE GEOLOGIA, 28., 1974, Porto Alegre. Anais... Porto Alegre: SBG, v.3, p.91-101.

IPT-INSTITUTO DE PESQUISAS TECNOLÓGICAS DO ESTADO DE SÃO PAULO. 1979. Potencial de biomassas vegetais para fins energéticos no Estado de São Paulo. São Paulo. (IPT, Relatório 12868,2 v.)

IPT-INSTITUTO DE PESQUISAS TECNOLÓGICAS DO ESTADO DE SÃO PAULO. 1992a. Sismotectônica e dinâmica superficial na área do alto rio Pardo (SP e $M G$ ). São Paulo. (IPT, Relatório 30 074, 4 v.)

IPT-INSTITUTO DE PESQUISAS TECNOLÓGICAS DO ESTADO DE SÃO PAULO. 1992b. Sismotectônica e dinâmica superficial na área da $\mathrm{PCH}$ Moji Guaçu. São Paulo. (IPT, Relatório 30 696, 3 v.)

MANCINI, F. \& RICCOMINI, C. 1994. Estilos estruturais da Formação Pindamonhangaba, Bacia de Taubaté, SP. In: CONGRESSO BRASILEIRO DE GEOLOGIA, 38., 1994, Camboriú. Bol. Res. Exp. Camboriú: SBG, v.1, p. 564-565.

MARTINS NETO, R.G. 1989. Novos insetos terciários do Estado de São Paulo. Rev. Bras. Geoc., v. 19, n. 3, p. 375-379.

MARTONNE, E. 1943. Problemas morfológicos do Brasil tropical atlântico. Rev. Bras. Geogr., v.5, n.4, p. 523-550.
MASSOLI, M. 1981. Geologia do Município de Santa Rita do Passa Quatro, SP. Rev. IG, v.2, n.2, p.35-45.

MATOS, S.L.F. 1995. O contato entre o Grupo Passa Dois e a Formação Pirambóia na borda leste da Bacia do Paraná no Estado de São Paulo. Dissertação de Mestrado apresentada ao Instituto de Geociências da USP, $110 \mathrm{p}$.

MELO, M.S. de. 1990. A Formação PariqueraAçu e depósitos relacionados: sedimentação, tectônica e geomorfogênese. São Paulo. 2llp. (Dissertação de Mestrado, IGUSP)

MELO, M.S. 1994. Depósitos cenozớicos da região centro-leste do Estado de São Paulo. In: WORKSHOP CIENTÍFICO DE PÓS-GRADUAÇÃO, 1., 1994, São Paulo. Resumos. São Paulo: IG-USP, p.5-6.

MELO, M.S. 1995. A Formação Rio Claro e depósitos associados: sedimentação neocenozóica na Depressão Periférica Paulista. São Paulo. 144p. (Tese de Doutorado, IG-USP)

MELO, M.S. \& PONÇANO, W.L. 1983. Gênese, distribuição e estratigrafia dos depósitos cenozóicos no Estado de São Paulo. São Paulo: IPT, 74 p. il. (IPT, Monografias 9)

MELO, M.S., COIMBRA, A.M., YBERT, J.-P. \& BRANDT NETO, M. 1996. Evidências paleoclimáticas em sedimentos neocenozóicos da porção centro-leste do Estado de São Paulo. Publicatio UEPG. Ponta Grossa, Univ. Estadual de Ponta Grossa, Ciências Exatas e da Terra, v. 2, n. 1, p. 71-84.

MELO, M.S., BRANDT NETO, M., COIMBRA, A.M., MORAES, M.C., TADDEO, J.S. \& CUCHIERATTO, G. 1997. Argilominerais de coberturas sedimentares cenozóicas do centro-leste do Estado de São Paulo. An. Acad. bras. Ci., v. 69 , n. 2, p. 227-241.

MEZZALIRA, S. 1961/62. Novas ocorrências de vegetais fósseis cenozóicos no Estado de São Paulo. São Paulo: $O I G G$, v. 15 , p. 73-94.

MEZZALIRA, S. 1965. Descrição geológica e geográfica das folhas de Piracicaba e São Carlos, SP. Bol. Inst. Geogr. Geol., n. 43, 42p. 
MODENESI, M.C. 1974. Níveis de erosão e formações superficiais na região de ItuSalto, SP. Rev. Bras. Geoc., v. 4, n. 4, p. 228-246.

MORAES REGO, L.F. 1933. As formações cenozoicas de S.Paulo. Ann. Esc. Polytechnica de São Paulo, ano II, 2. série, p. 231-267.

MÖRNER, N.-A. 1991. The Patagonian glaciations and the onset of general Quaternary-type glaciations on the globe. Bol. IG-USP. Pub. Esp., n. 8, p. 109-115.

MÖRNER, N.-A. 1993. Neotectonics, the new global tectonic regime during the last 3 $\mathrm{Ma}$ and the initiation of Ice Ages. An. Acad. bras. Ci., v. 62, Supl. 2, p. 295-301.

PENTEADO, M.M. 1969. A bacia de sedimentação de Rio Claro-Estado de São Paulo. Geographica, Rev. Soc. Geografia de Lisboa, v. 5, n. 17, p. 38-61.
PENTEADO, M.M. 1976. Geomorfologia do setor centro-ocidental da Depressão Periférica Paulista. São Paulo: IGEOG/USP, 86p. (Série Teses e Monografias, 22)

POTTER, P.E. \& PETTIJOHN, F.J. 1977. Paleocurrents and basin analysis. Berlin, Springer-Verlag, 425p.

RICCOMINI, C. 1989. O rift continental do Sudeste do Brasil. Tese de Doutorado, IG/USP, 256p.

SOARES, P.C. \& LANDIM, P.M.B. 1976. Depósitos cenozóicos na região Centro Sul do Brasil. Campinas: Notícia Geomorfológica, v. 16, n. 31, p. 17-39.

ZAINE, J.E. 1994. Geologia da Formação Rio Claro na folha Rio Claro (SP). Dissertação de Mestrado apresentada ao Instituto de Geociências e Ciências Exatas da UNESP, Campus de Rio Claro, 90p. 